\title{
Influence of mouse strain on ovarian tissue recovery after engraftment with angiogenic factor
}

\author{
Maïté Fransolet ${ }^{1}$, Laurie Henry ${ }^{1,2}$, Soraya Labied ${ }^{2}$, Marie-Caroline Masereel ${ }^{1,2}$, Silvia Blacher ${ }^{1}$, Agnès Noël ${ }^{1}$, \\ Jean-Michel Foidart ${ }^{1}$, Michelle Nisolle $\mathrm{e}^{1,2}$ and Carine Munaut ${ }^{1 *}$
}

\begin{abstract}
Background: For women facing gonadotoxic treatment, cryopreservation of ovarian tissue with subsequent retransplantation during remission is a promising technique for fertility preservation. However, follicle loss within grafted ovarian tissue can be caused by ischemia and progressive revascularization. Several xenograft models using different immunodeficient rodent lines are suitable for studying ovarian tissue survival and follicular viability after frozen-thawed ovarian cortex transplantation. SCID mice, which are deficient for functional B and T cells, are the most commonly used mice for ovarian xenograft studies. However, due to incomplete immunosuppression, NOD-SCID mice displaying low NK cell function and an absence of circulating complement might be more appropriate. The present study aims to define the most appropriate immunodeficient mouse strain for ovarian tissue xenotransplantation by comparing ovarian graft recovery in SCID and NOD-SCID mice following engraftment in the presence of isoform 111 of vascular endothelial growth factor.
\end{abstract}

Methods: Sheep ovarian cortex fragments were embedded in a collagen matrix, with or without VEGF 111 , before being stitched onto the ovaries of SCID and NOD-SCID mice. Transplants were recovered after 3 days to study early revascularization or after 3 weeks to evaluate follicle preservation and tissue fibrosis through histological analyses.

Results: At day 3, vessels were largely reorganized in the ovarian grafts of both mouse strains. After 3 weeks, the cortical tissue was clearly identifiable in SCID mice but not in NOD-SCID mice. Upon VEGF 111 treatment, vascularization was significantly improved 3 days after transplantation in SCID mice. This increase in vessel density was correlated with better follicular preservation in SCID mice 3 weeks after transplantation. Fibrosis was not decreased by VEGF treatment in either mouse strain.

Conclusions: Tissue architecture and follicular morphology were better preserved in ovarian tissues grafted in SCID mice in comparison with NOD-SCID mice. Moreover, tissue revascularization was improved in SCID mice by VEGF 111 graft treatment. Thus, we consider SCID mice to be the best murine model for studying ovarian tissue xenografts.

\section{Background}

To date, the future fertility of women with cancer remains a major concern because these women often face ovarian damage and premature ovarian failure after gonadotoxic treatments. For patients who need immediate chemotherapy or for prepubertal girls, ovarian cortex cryopreservation represents a promising fertility preservation technique [1]. Thus far, autologous transplantation of frozen/thawed ovarian tissue has allowed for the birth of more than 30 babies worldwide [2].

\footnotetext{
* Correspondence: c.munaut@ulg.ac.be

'Laboratory of Tumor and Developmental Biology, GIGA-R, University of Liège, Tour de Pathologie (B23), Sart Tilman, B-4000 Liège, Belgium Full list of author information is available at the end of the article
}

For autologous transplantation of frozen/thawed ovarian tissue, graft neovascularization remains a limiting factor for survival. Indeed, the lack of vascular anastomosis after tissue transplantation is responsible for early transplant ischemia, which decreases the ovarian tissue survival rate and gives rise to massive follicular loss by apoptosis [3-7]. To study ovarian tissue survival and follicular viability after frozen-thawed ovarian cortex transplantation, several xenograft models using different immunodeficient rodent lines have been developed and published. Indeed, in vivo research using preclinical models represent a crucial step before clinical application. Severe combined immunodeficient (SCID) mice were the first and most commonly used mice for ovarian xenografts $[5,8,9]$. This mouse strain is 
characterized by the scid mutation, which leads to a defect in the recombination of antigen receptor genes, impairing the capacity to generate functional $\mathrm{B}$ and $\mathrm{T}$ lymphocytes $[10,11]$. This deficiency contributes to the acceptance of xenogeneic grafts without severe rejection. However, in 2 to $25 \%$ of young adult mice, the mutation is not completely stable [12]. In this context, development and maturation of lymphocytes can occur and lead to incomplete immunosuppression, which may limit the grafting efficiency of xenogeneic tissues [13]. Therefore, long term foreign tissue rejection represents an important issue in SCID mice. A few years after SCID mice generation, the scid mutation was transferred into a Non-Obese Diabetic (NOD) background. This transfer leads to NOD-SCID mice, which have reduced NK cell activity in addition to the deficiency in functional B and T cells [14]. Moreover, their ability to activate some components of the complement system is impaired, and these mice are markedly deficient in macrophages [15]. Based on these multiple defects in innate and adaptive immunity, the NOD-SCID strain is expected to be more promising as a tool for xenotransplantation.

To reduce the hypoxic period after tissue transplantation and improve follicular preservation, angiogenesis can be stimulated by vascular endothelial growth factor, which is the main signaling protein that regulates new vessel formation from pre-existing vessels. The effects of two VEGF-A isoforms, VEGF 111 and VEGF 165 , were recently tested in a xenograft model developed in our lab using SCID mice [16,17]. These VEGF isoforms were chosen for their unique properties; VEGF 111 is soluble and resistant to proteolysis, whereas $\mathrm{VEGF}_{165}$ is additionally anchored to the extracellular matrix. Both VEGF isoforms increase blood vessel recruitment and functional angiogenesis.

Due to differences in immune response, the mouse strain used in the xenograft model can significantly impact the results. The aim of the present study was to determine the most appropriate experimental model, SCID or NOD-SCID mice, for ovarian cortex transplantation. Histological and functional features of frozen-thawed sheep ovarian cortex with or without $\mathrm{VEGF}_{111}$ treatment were subsequently analyzed.

\section{Methods}

\section{Collection and preparation of ovarian tissue}

Ovarian cortex from sheep was obtained and prepared as described previously [16]. The Animal Ethics Committee of the University of Liège approved the use of sheep ovarian tissue obtained from the Ovine Research Center (University of Namur). Briefly, after euthanasia, ovaries were transferred and kept at $4{ }^{\circ} \mathrm{C}$ until processing in Leibovitz L-15 medium (Lonza, Verviers, Belgium, BE12-700 F) supplemented with 10\% normal sheep serum (Hormonology Laboratory, Marloie, Belgium). In the laboratory, the medulla was removed and the cortex was cut into strips $(5 \times 5 \times 1 \mathrm{~mm})$ before equilibration during $30 \mathrm{~min}$ at $4^{\circ} \mathrm{C}$ in cryopreservative medium containing Leibovitz L-15 medium supplemented with 10\% normal sheep serum, $10 \%$ dimethylsulfoxide $(1.5 \mathrm{M})$ (Sigma-Aldrich, Bornem, Belgium) and 0.1 M sucrose.

\section{Freezing and thawing of ovarian tissue}

Ovarian biopsies were cooled in a programmable freezer (CL-8800i system, CryoLogic, Mulgrave, Victoria, Australia) in cryovial tubes (Simport, Montreal, Quebec, Canada) as described previously [18] and stored in liquid nitrogen until transplantation. At transplantation, the cryovials were incubated at room temperature for $2 \mathrm{~min}$ and thawed by rapid immersion at $37^{\circ} \mathrm{C}$ in a water bath. To remove the cryoprotectant, cortical fragments were washed three times for $5 \mathrm{~min}$ at $37^{\circ} \mathrm{C}$ in serum-free Leibovitz medium.

\section{Ovarian transplant encapsulation}

Cortical biopsies of $2.5 \times 2.5 \times 1 \mathrm{~mm}$ from 20 ewes were embedded in a three-dimensional collagen matrix as previously described [16]. On a heating plate, a first layer of type I collagen extracted from the tail tendons of rats [19] was poured in an agar ring. The collagen matrix was prepared by mixing 9 volumes of type I collagen $(2.4 \mathrm{mg} / \mathrm{ml}), 1$ volume of $10 \times$ minimal essential medium and approximately 0.1 volume of $1 \mathrm{M} \mathrm{NaOH}$ to adjust the $\mathrm{pH}$ to 7.4. After polymerization, frozen-thawed ovarian strips pierced with surgical thread were placed and overlaid by a second layer of type I collagen.

VEGF $_{111}$ was produced and purified as previously described $[16,20]$ and then included in the collagen of treated group at a concentration of $100 \mathrm{nM}$.

\section{Mouse transplantation and sacrifice}

Eight-week-old severe combined immunodeficient (SCID, $\mathrm{n}=32$ ) or non-obese diabetic SCID (NOD-SCID, $\mathrm{n}=19$ ) mice (Charles River, Saint-Germain-sur-l'Arbresle, France) were anesthetized with an intraperitoneal injection of ketamine $(100 \mathrm{mg} / \mathrm{kg})$ and xylazine $(10 \mathrm{mg} / \mathrm{kg})$. An encapsulated ovarian biopsy was stitched onto the ovary with a 7-0 Prolene suture. Fragments from 2 different ewes were usually used per experiment.

To study the functional vascular network, $200 \mu \mathrm{l}$ of dextran/fluorescein isothiocyanate (FITC) $(2.5 \mathrm{mg} / \mathrm{ml}$ in PBS) (Sigma-Aldrich, Belgium) was intravenously injected $3 \mathrm{~min}$ before sacrifice. Animals were euthanized by cervical dislocation 3 days or 3 weeks after grafting. The sheep ovarian transplants were recovered and fixed in $4 \%$ formaldehyde.

\section{Histological assessment}

Each graft was cut into 5- $\mu$ m-thick serial sections. Ten sections per transplant, which covered the entire ovarian 
fragment, were stained with haematoxylin and eosin (H\&E).

To detect the functional vascular network, immunostaining was performed in one step. Sections were deparaffinized and rehydrated, and endogenous peroxidase activity was blocked by incubating the sections in 3\% hydrogen peroxide for $20 \mathrm{~min}$ at room temperature (RT). Nonspecific binding sites were blocked by incubation with phosphate-buffered saline (PBS) containing 10\% bovine serum albumin for $30 \mathrm{~min}$ at RT. The sections were incubated with a ready-to-use anti-fluorescein antibody (Converter-POD, Roche, France), which directly recognized the FITC molecules fixed on dextran, for $30 \mathrm{~min}$ at RT. Negative control slides were also performed by replacing the antibody with phosphate-buffered saline (PBS). The 3,3'-diaminobenzidine substrate (K3468, Dako, Belgium) allowed the visualization of positively stained cells, and the sections were counterstained with haematoxylin.

Fibrosis was evaluated using saffron staining. Sections were incubated in 1\% saffron solution (Microm Microtech, Francheville, France) in $100 \%$ ethanol for $10 \mathrm{~min}$ at $37^{\circ} \mathrm{C}$.

\section{Virtual image acquisition}

Slides were digitized in brightfield at $20 \times$ magnification using the NanoZoomer 2.0-HT C9600-13 (Hamamatsu Photonics, K.K., Japan), a high-speed and high-resolution digital slide scanner system. Digital images were acquired in .ndpi format and visualized with NDP.view software (Olympus) on a standard PC.

\section{Histological analysis of follicle numbers}

At least $10 \mathrm{H} \& \mathrm{E}$ sections per fragment were analyzed by Image J software in order to limit the impact of natural follicular heterogeneity on experimental results [21]. Follicles were quantified manually and, to avoid double counting, only follicles with a visible nucleus were taken into account. Follicles were then classified according to their maturity (primordial, primary or secondary follicles). Follicular densities (number $/ \mathrm{mm}^{2}$ ) were calculated after a manual surrounding of the cortical surface (Image J software).

\section{Vascular network analysis}

Stained vessels were drawn manually on digital images and transformed to obtain a binarized image in which the intensity of pixels representing vessels was set to 1 and that corresponding to the background was set to 0 . The number of vessel sections was measured automatically on the binary images [22,23]. The results are expressed as unity of area of ovarian tissue. An image analysis was conducted using MATLAB 8.1.0.604 (R2013a) software (Mathworks, Inc.).

\section{Fibrosis analysis}

Digital images of saffron-stained tissue slices were analyzed using ImageJ software (National Institutes of Health, USA). Digitized color images were first decomposed into their red, green, and blue components. To enhance the features of fibrosis, the blue component was subtracted from the red component. The resulting images were then binarized using an appropriate threshold. In this method, pixels that were associated with fibrosis were assigned a value of 1 , and pixels that were associated with nonfibrotic tissue were assigned a value of 0 . The ratio of the surface area that was occupied by fibrotic tissue to the total surface area of the tissue represented the proportion of fibrotic tissue in each transplant.

\section{Statistical analysis}

Statistical analyses were performed using GraphPad Prism software (GraphPad, San Diego, CA). The MannWhitney test was applied for comparisons between two different groups. The proportion of positive fragments for dextran/FITC-stained blood vessels was compared with a chi-square test. A probability of $p<0.05$ was considered to be statistically significant.

\section{Results}

\section{Graft recovery and histological examination}

Mice were sacrificed 3 days or 3 weeks after transplantation, and all 102 ovarian xenografts were recovered from the SCID $(n=32)$ and NOD-SCID $(n=19)$ mice. For technical reasons, two transplants could not be analyzed. The cortex and medulla were clearly detectable on fresh ovarian tissue. Most of the follicles were located in the cortex, whereas the medulla contained a highly vascular stroma (Figure 1A). After grafting, haematoxylin and eosin staining of tissue sections revealed major remodeling of the preexisting vessels compared to fresh tissue as soon as 3 days after transplantation in both mouse strains (Figure 1B, C). Nevertheless, at day 3 post transplantation, the tissue architecture, cortex and medulla were still recognizable. In sharp contrast, grafts recovered after 3 weeks of transplantation displayed extensive tissue remodeling in both mouse strains (Figure 1D, E). The overall tissue histology displayed better morphology in SCID compared to NOD-SCID mice. The cortex of the biopsy transplanted in SCID mice was easily identified, while the tissue grafted in NOD-SCID mice appeared more disorganized.

No effect of $\mathrm{VEGF}_{111}$ on ovarian tissue fragment histology was observed at 3 days or 3 weeks post transplantation.

\section{Graft neovascularization}

Dextran/FITC injections were performed before sacrifice, and perfused transplants were evaluated at day 3 post transplantation by immunohistochemical detection 


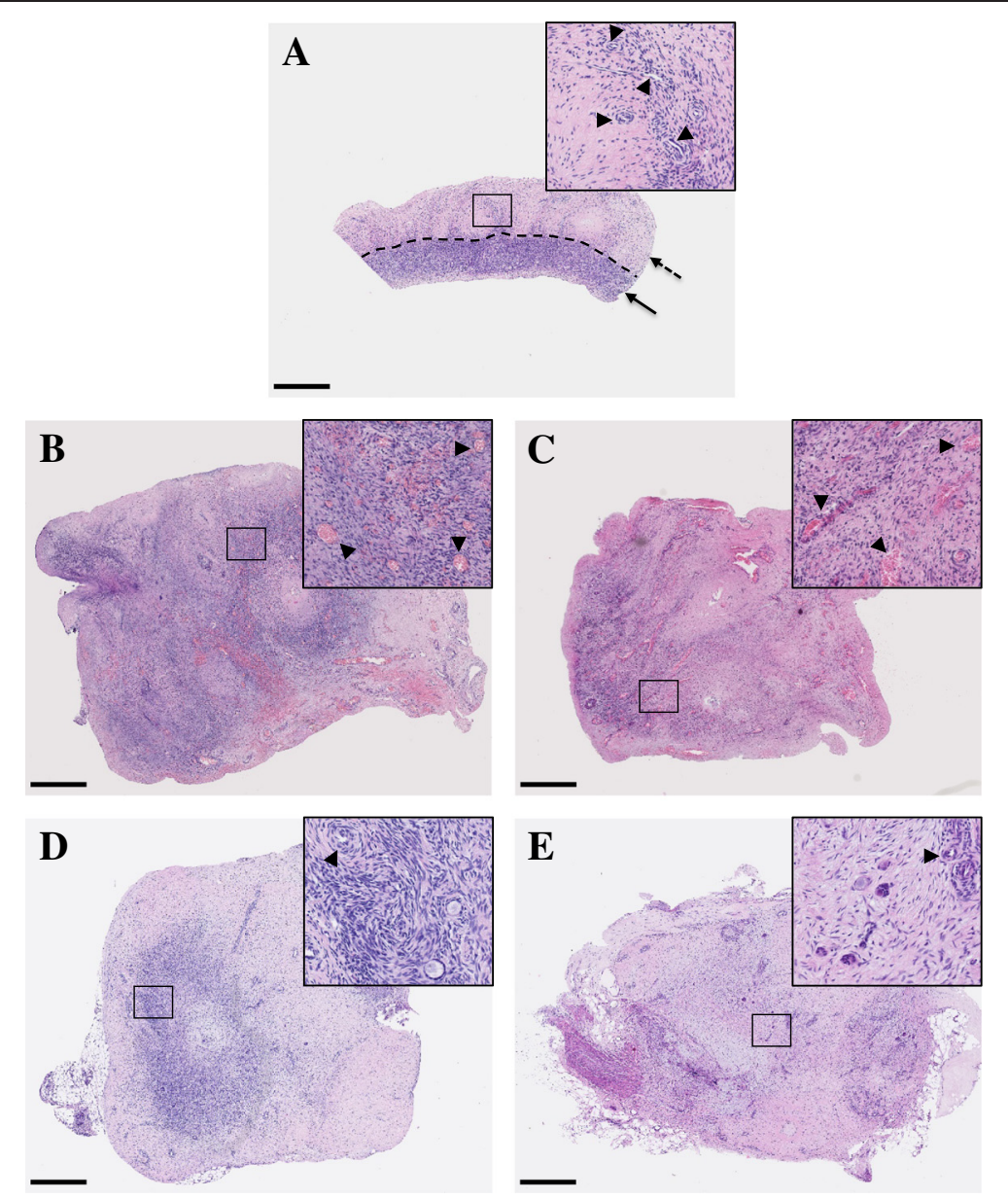

Figure 1 Histological analysis of haematoxylin and eosin sections of ovarian tissue. Representative illustrations of fresh ovarian tissue before cryopreservation (the cortex and medulla are identified by a plain and dotted arrow, respectively) (A); ovarian control grafts 3 days after transplantation in SCID mice (B) and NOD-SCID mice (C); ovarian control grafts 3 weeks after transplantation in SCID mice (D) and NOD-SCID mice (E). Indicates vessels. Scale bar: $500 \mu \mathrm{M}$. Images are representative of at least 2 experiments.

of FITC (Figure 2). Treatment with VEGF $_{111}$ improved the percentage of perfused transplants only in SCID mice (Table 1). Functional blood vessel density was also higher in fragments grafted in SCID mice following treatment with $\mathrm{VEGF}_{111}$ (Figure 3).

\section{Follicular morphology and density}

Morphologically, follicles from tissue grafted for 3 weeks in both mouse strains were indistinguishable from those from fresh tissue (Figure 4A). Follicles from SCID mouse transplanted tissue were round and contained fewer vacuoles (Figure 4B). In NOD-SCID mice, despite a wellorganized granulosa cell layer and intact oocytes, follicles displayed ooplasm with many vacuoles (Figure 4C).

To determine if ovarian cortex treatment with $\mathrm{VEGF}_{111}$ could improve follicular survival, follicular density was evaluated in SCID and NOD-SCID mice (Figure 4D, E). Compared to vehicle treated controls, $\mathrm{VEGF}_{111}$ had an impact on primordial follicle preservation in SCID mice.

\section{Fibrosis analysis}

To further the tissue remodeling analysis, fibrosis was evaluated by saffron staining. Analysis of fresh and frozenthawed tissues compared to tissue grafted over 3 weeks showed that fibrosis was significantly increased after transplantation. Among grafted ovarian tissues, fibrotic areas were found to be similar in controls and in VEGF-treated groups, regardless of the mouse strain (Figure 5).

\section{Discussion}

Fertility restoration after transplantation of frozen-thawed ovarian tissue is a major concern in reproductive medicine. To improve the process, many xenograft models have been used [5]. Indeed, establishing rapid perfusion of the transplant associated with a significant follicular preservation in a mouse model could be very useful in the clinic for human ovarian tissue autotransplantation. This study was undertaken to compare results obtained after ovarian tissue xenotransplantation in two different 


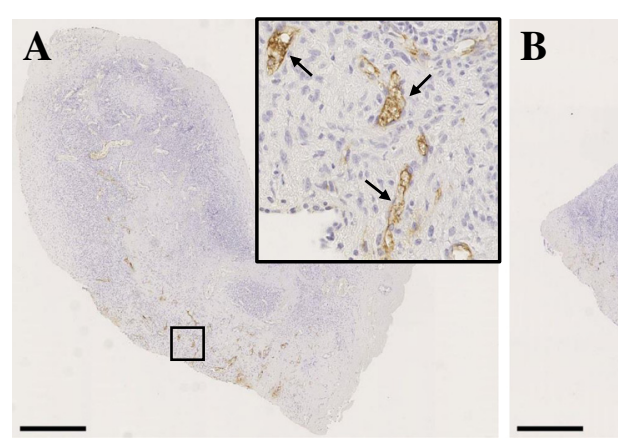

Figure 2 Functional vascular network identification in ovarian tissue 3 days after transplantation in SCID and NOD-SCID mice. Representative illustrations of functional blood vessels (identified by plain arrows) revealed by dextran-FITC immunostaining in VEGF 111 treated fragments grafted in SCID (A) and NOD-SCID (B) mice. Scale bar: $500 \mu \mathrm{M}$. Images are representative of at least 2 experiments.

immunodeficient mice strains. Using a pre-clinical mouse model, we provide evidence that the morphological features of transplanted ovarian tissue could be impacted by the mouse strain. Our results indicate that graft perfusion and follicular preservation were better in ovarian fragments grafted in SCID mice.

The period before revascularization of frozen-thawed ovarian tissue grafts appears to be the main factor responsible for the ischemic damage that decreases the lifespan of the transplant $[3,24]$. The electron paramagnetic resonance oximetry technique highlighted the observation that progressive revascularization of the tissue starts 5 days after grafting [25]. Therefore, several xenograft studies have been performed to restore earlier blood supply in an attempt to improve follicular preservation by limiting ischemic damage. Surprisingly, although angiogenesis was successively promoted, better vascularization was not always associated with follicular preservation improvement [16,17,26-29]. In line with these previous publications, our results confirm the angiogenic effect of $\mathrm{VEGF}_{111}$. However, the impact on primordial follicular preservation was observed only in SCID mice whose xenografts were treated with $\mathrm{VEGF}_{111}$. Primary follicles were better preserved in NOD-SCID than in SCID mice. However, the low density of primary follicles observed in the biopsies after 3 weeks of transplantation suggests that the

Table 1 Percentage of ovarian transplants positive for dextran/FITC staining 3 days after transplantation in SCID and NOD-SCID mice

\begin{tabular}{lll}
\hline & $\mathbf{n}(\%)$ & $\mathbf{n}(\%)$ \\
\hline SCID & Negative & Positive \\
$C T(n=21)$ & $13(62)$ & $8(38)$ \\
$\operatorname{VEGF}_{111}(n=19)$ & $8(42)$ & $11(58)$ \\
NOD-SCID & Negative & Positive \\
$C T(n=8)$ & $2(25)$ & $6(75)$ \\
$\operatorname{VEGF}_{111}(n=6)$ & $3(50)$ & $3(50)$ \\
\hline
\end{tabular}

biological significance of these results is questionable. Moreover, heterogeneous follicular distribution within sheep ovarian cortex may have an impact on the results [21]. Follicle preservation or functional vascular network and fibrotic surface analyses did not reveal any significant differences between the two mouse strains; however, as previously described, we confirmed that ovarian tissue transplantation itself induces fibrosis [6]. Histological analysis indicates that ovarian tissue transplantation in SCID mice better preserves global tissue architecture and follicular morphology in comparison to tissue grafted in NOD-SCID mice. Other studies have also reported that damage to stromal cells as well as follicular alterations occur during the first days after transplantation [6,7]. Immunodeficient mice constitute a valuable tool for studying xenografts and tumorigenesis. Since 1960, athymic mice (nude) have been the standard for establishing in vivo models of human malignancies. An attractive alternative to this model is SCID mice, which lack functional T and B cells but retain normal natural killer (NK) cell activity. NOD-SCID mice have additional immunologic defects, including low NK cell function and absence of circulating

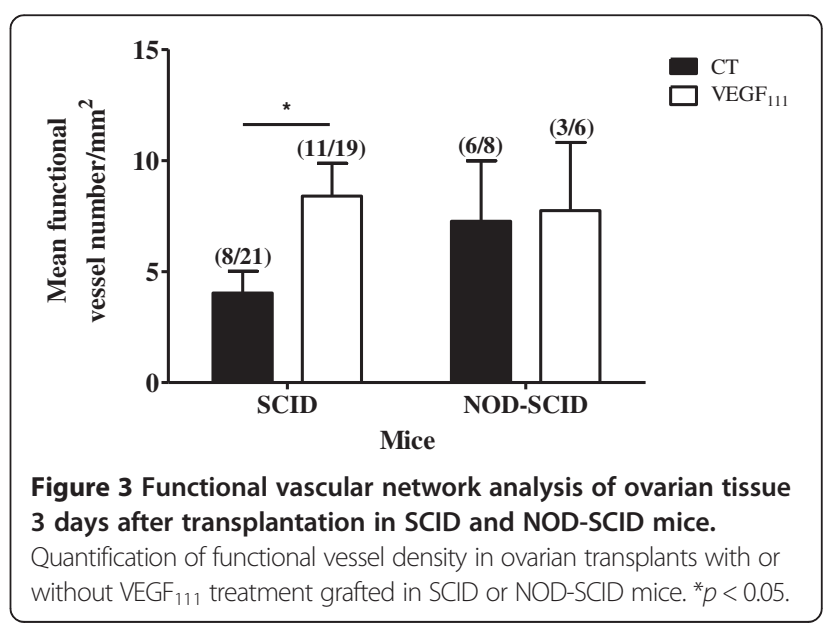




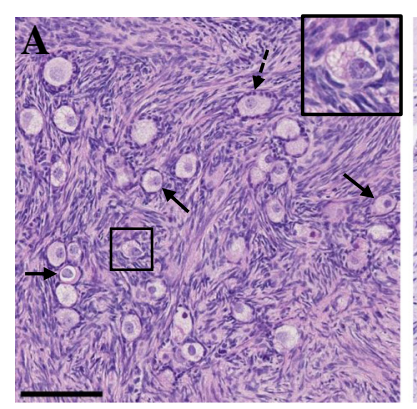

D

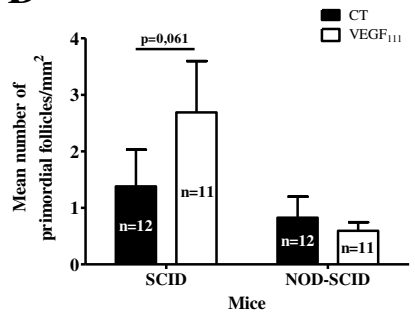

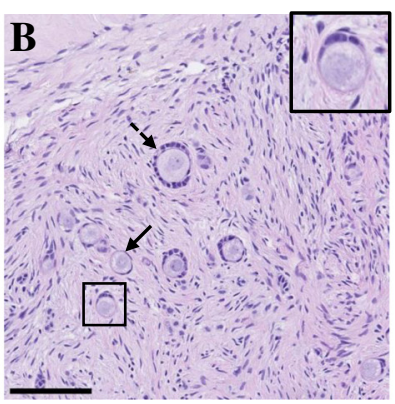

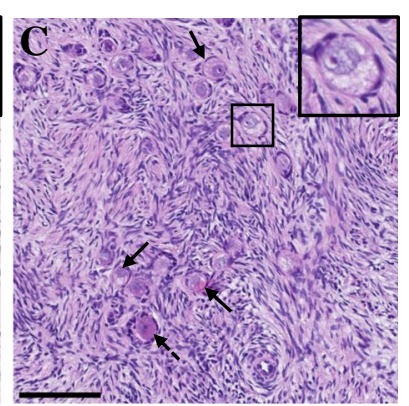

$\mathbf{E}$

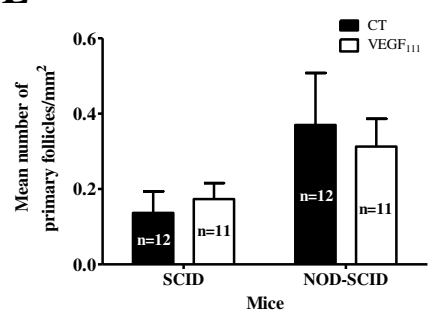

Figure 4 Follicle analysis of ovarian tissue 3 weeks after transplantation in SCID and NOD-SCID mice. H\&E sections of fresh ovarian tissue (A) and ovarian control tissue transplanted in SCID (B) and NOD-SCID (C) mice (primordial and primary follicles are identified by plain and dotted arrows, respectively). Quantification of primordial (D) and primary (E) follicle density in ovarian transplants with or without VEGF ${ }_{111}$ treatment and grafted in SCID or NOD-SCID mice. Scale bar: $100 \mu \mathrm{M}$. Images are representative of at least 2 experiments.

complement. Currently, there is no consensus in the literature regarding the type of immunodeficient mice to use for frozen-thawed ovarian tissue xenotransplantation. Recently, different grafting sites were evaluated in nude mice; all transplantation sites equally supported follicular growth and preserved quiescent follicles and stromal fibrosis [30].

In the context of ovarian tissue recovery after autotransplantation, immunity may play an important role that is overlooked in studies using immunodeficient mice for xenografts. Indeed, to be more representative of the clinical process, the use of humanized animal models could be interesting [31]. In fact, to observe the "pure" human immune response, the recipient mice should express no mouse major histocompatibility complex
(MHC) genes or express certain human leukocyte antigens (HLA).

\section{Conclusions}

To our knowledge, this is the first study undertaken to test and compare two different immunodeficient mouse strains with a BALB/c background (SCID and NOD-SCID) as hosts and to assess the benefit of grafts treated with $\mathrm{VEGF}_{111}$. Our results indicate that sheep ovarian tissue xenografts in SCID and NOD-SCID mice are both suitable for studying graft recovery. However, based on histologic analysis, the overall tissue morphology is better preserved in SCID mice. Moreover, in this mouse strain, grafted ovarian tissues treated with VEGF isoform 111 display better graft perfusion and primordial follicle preservation.

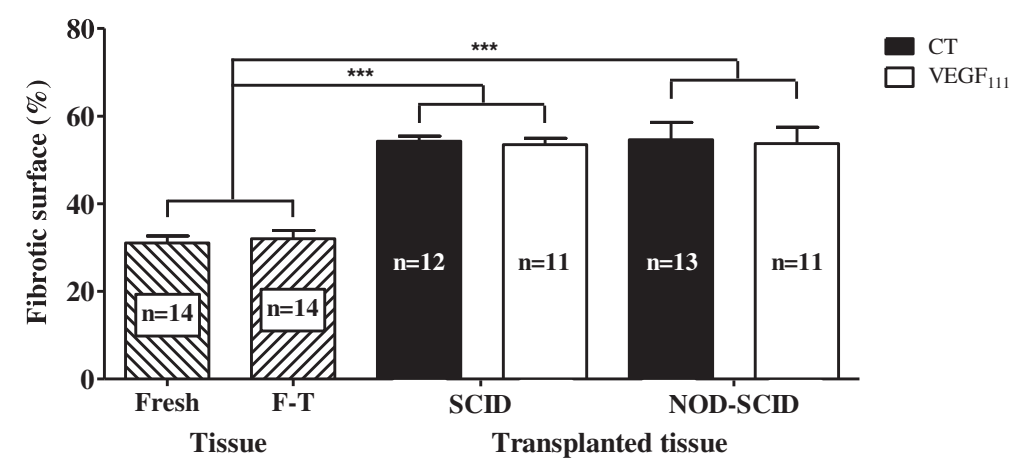

Figure 5 Fibrosis analysis of ovarian tissue 3 weeks after transplantation in SCID and NOD-SCID mice. Percentage of fibrotic tissue in fresh and frozen-thawed (F-T) ovarian biopsies and ovarian transplants grafted in SCID and NOD-SCID mice. ${ }^{* *} p<0.001$. 


\section{Abbreviations}

SCID: Severe combined immunodeficient; NOD-SCID: Non-obese diabetic severe combined immunodeficient; NK: Natural killer; VEGF: Vascular endothelial growth factor; FITC: Fluorescein isothiocyanate; RT: Room temperature; PBS: Phosphate-buffered saline; MHC: Major histocompatibility complex; HLA: Human leukocyte antigens.

\section{Competing interests}

The authors declare that they have no competing interests.

\section{Authors' contributions}

MF performed experiments, interpreted data and wrote the manuscript. $\mathrm{LH}$ interpreted the VEGF 111 -grafted SCID mice data. SL designed the study, performed experiments and interpreted data. MCM contributed to follicular quantification. SB performed the computer images analysis. AN revised the manuscript. JMF conceived the study and corrected the manuscript. MN conceived and designed the study and corrected the manuscript. CM conceived and designed the study, interpreted data, corrected the manuscript and substantially contributed to critical revisions. All authors read and approved the final manuscript.

\section{Acknowledgments}

The authors thank I. Dasoul, E. Feyereisen and P. Gavitelli for their excellent histology and immunostaining assistance. The authors are very grateful to F. Olivier and M. Dehuy for their help with the animals and to Dr. N. Kirshvink, a veterinarian at the Ovine Research Center (University of Namur). This work was supported by grants from the Fonds de la Recherche Scientifique Médicale, the Fonds de la Recherche Scientifique - FNRS (F.R.S.-FNRS, Belgium), the Foundation against Cancer (foundation of public interest, Belgium), the Fonds spéciaux de la Recherche (University of Liège), the Centre Anticancéreux près I'Université de Liège, the Fonds Léon Frederica (University of Liège), the Direction Générale Opérationnelle de l'Economie, de l'Emploi et de la Recherche from the S.P.W. (Région Wallonne, Belgium), the Fonds d'Investissements de la Recherche Scientifique (F.I.R.S., CHU, Liège, Belgium), the Interuniversity Attraction Poles Programme - Belgian Science Policy (Brussels, Belgium), and the Plan National Cancer (Service Public Fédéral).

\section{Author details}

'Laboratory of Tumor and Developmental Biology, GIGA-R, University of Liège, Tour de Pathologie (B23), Sart Tilman, B-4000 Liège, Belgium. ${ }^{2}$ Department of Obstetrics and Gynecology, University of Liège, Hôpital de la Citadelle, B-4000 Liège, Belgium.

Received: 29 October 2014 Accepted: 10 March 2015

Published online: 27 March 2015

\section{References}

1. Rodriguez-Wallberg KA, Oktay K. Recent advances in oocyte and ovarian tissue cryopreservation and transplantation. Best Pract Res Clin Obstet Gynaecol. 2012;26(3):391-405

2. Meirow D, Ra'anani H, Biderman H. Ovarian tissue cryopreservation and transplantation: a realistic, effective technology for fertility preservation. Methods Mol Biol. 2014;1154:455-73.

3. Baird DT, Webb R, Campbell BK, Harkness LM, Gosden RG. Long-Term Ovarian Function in Sheep after Ovariectomy and Transplantation of Autografts Stored at -196 C. Endocrinology. 1999;140(1):462-71.

4. Liu J, Van der Elst J, Van den Broecke R, Dhont M. Early massive follicle loss and apoptosis in heterotopically grafted newborn mouse ovaries. Hum Reprod. 2002;17(3):605-11.

5. Aubard Y. Ovarian tissue xenografting. Eur J Obstet Gynecol Reprod Biol. 2003;108(1):14-8.

6. Nisolle M, Casanas-Roux F, Qu J, Motta P, Donnez J. Histologic and ultrastructural evaluation of fresh and frozen-thawed human ovarian xenografts in nude mice. Fertil Steril. 2000;74(1):122-9.

7. Yang H, Lee HH, Lee HC, Ko DS, Kim SS. Assessment of vascular endothelial growth factor expression and apoptosis in the ovarian graft: can exogenous gonadotropin promote angiogenesis after ovarian transplantation? Fertil Steril. 2008;90(4 Suppl):1550-8.

8. Gosden RG, Boulton MI, Grant K, Webb R. Follicular development from ovarian xenografts in SCID mice. J Reprod Fertil. 1994;101:619-23.
9. Weissman A, Gotlieb L, Colgan T, Jurisicova A, Greenblatt EM, Casper RF. Preliminary experience with subcutaneous human ovarian cortex transplantation in the NOD-SCID mouse. Biol Reprod. 1999:60:1462-7.

10. Bosma GC, Custer RP, Bosma MJ. A severe combined immunodeficiency mutation in the mouse. Nature. 1983:301(5900):527-30.

11. Custer RP, Bosma GC, Bosma MJ. Severe combined immunodeficiency (SCID) in the mouse. Pathology, reconstitution, neoplasms. Am J Pathol. 1985;120(3):464-77.

12. Bosma GC, Fried M, Custer RP, Carroll AM, Gibson DM, Bosma MJ. Evidence of functional lymphocytes in some (leaky) scid mice. J Exp Med. 1988;167:1016-33.

13. Bosma MJ, Carroll AM. The SCID mouse mutant: definition, characterization, and potential uses. Annu Rev Immunol. 1991;9:323-50.

14. Prochazka M, Gaskins HR, Shultz LD, Leiter EH. The nonobese diabetic scid mouse: model for spontaneous thymomagenesis associated with immunodeficiency. Immunology. 1992;88:3290-4.

15. Shultz LD, Schweitzer PA, Christianson SW, Gott B, Schweitzer IB, Tennent B, et al. Multiple defects in innate and adaptive immunologic function in NOD/LtSz-scid mice. J Immunol. 1995;154(1):180-91.

16. Labied S, Delforge Y, Munaut C, Blacher S, Colige A, Delcombel R, et al. Isoform 111 of Vascular Endothelial Growth Factor (VEGF111) Improves Angiogenesis of Ovarian Tissue Xenotransplantation. Transplantation. 2013;95(3):426-33.

17. Henry L, Labied S, Fransolet M, Kirschvink N, Blacher S, Noel A, et al. Isoform 165 of vascular endothelial growth factor in collagen matrix improves ovine cryopreserved ovarian tissue revascularisation after xenotransplantation in mice. Reprod Biol Endocrinol. 2015;13(1):12.

18. Gosden RG, Baird DT, Wade JC, Webb R. Restoration of fertility to oophorectomized sheep by ovarian autografts stored at -196 degrees C. Hum Reprod. 1994;9(4):597-603.

19. Fusenig NE, Limat A, Stark HJ, Breitkreutz D. Modulation of the differentiated phenotype of keratinocytes of the hair follicle and from epidermis. J Dermatol Sci. 1994;7(Suppl):S142-51.

20. Mineur P, Colige AC, Deroanne CF, Dubail J, Kesteloot F, Habraken Y, et al. Newly identified biologically active and proteolysis-resistant VEGF-A isoform VEGF111 is induced by genotoxic agents. J Cell Biol. 2007;179(6):1261-73

21. Fransolet M, Labied S, Henry L, Masereel M-C, Rozet E, Kirschvink N, et al. Strategies for using the sheep ovarian cortex as a model in reproductive medicine. PloS one. 2014;9(3):e91073.

22. Balsat C, Blacher S, Signolle N, Beliard A, Munaut C, Goffin F, et al Whole slide quantification of stromal lymphatic vessel distribution and peritumoral lymphatic vessel density in early invasive cervical cancer: a method description. ISRN obstet gynecol. 2011;2011:354861.

23. Chantraine F, Blacher S, Berndt S, Palacios-Jaraquemada J, Sarioglu N Nisolle $\mathrm{M}$, et al. Abnormal vascular architecture at the placental-maternal interface in placenta increta. Am J Obstet Gynecol. 2012;207(3):188. e181-189.

24. Imthurn B, Cox SL, Jenkin G, Trounson AO, Shaw JM. Gonadotrophin administration can benefit ovarian tissue grafted to the body wall: implications for human ovarian grafting. Mol Cell Endocrinol. 2000;163(1-2):141-6

25. Van Eyck AS, Jordan BF, Gallez B, Heilier JF, Van Langendonckt A, Donnez J. Electron paramagnetic resonance as a tool to evaluate human ovarian tissue reoxygenation after xenografting. Fertil Steril. 2009;92(1):374-81.

26. Wu D, Lei Y, Tong Y, Tang F, Qian Y, Zhou Y. Angiogenesis of the frozen-thawed human fetal ovarian tissue at the early stage after xenotransplantation and the positive effect of Salviae miltiorrhizae. Anat Rec(Hoboken). 2010;293(12):2154-62.

27. Commin L, Buff S, Rosset E, Galet C, Allard A, Bruyere P, et al. Follicle development in cryopreserved bitch ovarian tissue grafted to immunodeficient mouse. Reprod Fertil Dev. 2012;24(3):461-71.

28. Soleimani R, Heytens E, Oktay K. Enhancement of neoangiogenesis and follicle survival by sphingosine-1-phosphate in human ovarian tissue xenotransplants. PLoS One. 2011;6(4):e19475.

29. Friedman O, Orvieto R, Fisch B, Felz C, Freud E, Ben-Haroush A, et al. Possible improvements in human ovarian grafting by various host and graft treatments. Hum Reprod. 2012;27(2):474-82. 
30. Dath C, Van Eyck AS, Dolmans MM, Romeu L, Delle Vigne L, Donnez J, et al. Xenotransplantation of human ovarian tissue to nude mice: comparison between four grafting sites. Hum Reprod. 2010;25(7):1734-43.

31. Zhang B, Duan Z, Zhao Y. Mouse models with human immunity and their application in biomedical research. J Cell Mol Med. 2009:13(6):1043-58

Submit your next manuscript to BioMed Central and take full advantage of:

- Convenient online submission

- Thorough peer review

- No space constraints or color figure charges

- Immediate publication on acceptance

- Inclusion in PubMed, CAS, Scopus and Google Scholar

- Research which is freely available for redistribution 